\section{O conceito de vulnerabilidade e seus sentidos para as políticas públicas de saúde e assistência social}

The concept of vulnerability and its meanings for public policies in health and social welfare

El concepto de vulnerabilidad y su sentido para
las políticas públicas de salud y asistencia social
Michelly Eustáquia do Carmo 1,2

Francini Lube Guizardi 2

doi: 10.1590/0102-311X00101417

\section{Correspondência}

M. E. Carmo

Ministério do Desenvolvimento Social.

SGAN 914, Brasília, DF 70790-148, Brasil.

michelly.carmo@fiocruz.br

1 Ministério do Desenvolvimento Social, Brasília, Brasil.

2 Escola Fiocruz de Governo, Fundação Oswaldo Cruz, Brasília, Brasil. produzida nas duas últimas décadas sobre o tema. Não há vasta produção teórica que contemple a temática. Contudo, mesmo conceitualmente impreciso, o termo vulnerabilidade amplia a compreensão dos múltiplos fatores que fragilizam os sujeitos no exercício de sua cidadania. As ações profissionais no âmbito das políticas de saúde e assistência social e o imaginário social são forjados pela incorporação de conceitos que podem tanto reduzir quanto reforçar vulnerabilidades.

Assistência Social; Seguridade Social; Política de Saúde 


\section{Introdução}

Fruto de intenso debate entre diferentes categorias profissionais, acadêmicas, populares e políticas, o processo constituinte brasileiro, na década de 1980, impulsionado pelo movimento de redemocratização nacional, permitiu que entrassem na Constituição Federal de 1988 institutos legais de envergadura ampla, positivando garantias que ensaiavam um projeto de Estado de bem-estar social. No texto constitucional, a previdência social - restrita aos trabalhadores contribuintes do sistema previdenciário -, a assistência social e a saúde (com prestação sem contrapartida contributiva direta da população) estão compreendidas em um sistema de seguridade social que integra ações de iniciativa do poder público e da sociedade para a garantia de direitos de cidadania à população.

Com as reformas, ou contrarreformas, de direção neoliberal 1,2,3,4, ocorridas nos últimos anos no Brasil, as políticas públicas de seguridade social sofreram impactos limitantes para a sua cobertura. Ainda que seja possível admitir avanços no desenho do sistema de proteção social brasileiro, há também que se considerar o convívio deste modelo de tendência abrangente e universal com os projetos de retração de benefícios, caracterizados por retrocessos e constantes ameaças de retirada de direitos já conquistados.

Situada em um campo de frequentes disputas entre diferentes projetos societários, que revelam concepções distintas de Estado, a seguridade social não contributiva brasileira depara-se com uma correlação de forças que não permite a efetivação de seu princípio de universalidade, fazendo com que acabe por focalizar-se nos sujeitos em situação de vulnerabilidade, além de vivenciar um estado de inconclusão 5,6 tanto na sua consecução quanto na ideia de cidadania que carrega.

Ao dispor sobre organização e funcionamento dos serviços de saúde, na lógica de um sistema único, a Legislação Brasileira, em 1990 7, já concebia que as condições de promoção, proteção e recuperação da saúde envolvem fatores como alimentação, trabalho, renda, saneamento básico, acesso a bens, serviços e informação 8. Assenta-se, portanto, a concepção de determinantes sociais de saúde, relacionada à vulnerabilidade ao buscar se contrapor ao paradigma estritamente biológico para a caracterização do processo saúde-doença. Tal perspectiva traz uma compreensão mais alargada das ações da política de saúde sobre os múltiplos fatores que incidem no cotidiano de vida dos sujeitos em seus territórios, contribuindo para a promoção ou deterioração dos seus estados de saúde.

O início da regulamentação da política pública de assistência social aconteceu em um cenário de conflitos e contradições, na sequência das normativas da política pública de saúde. Em 2004, quando foi instituída, a Política Nacional de Assistência Social (PNAS) explicitou em seu texto que a vulnerabilidade social, expressa por diferentes situações que podem acometer os sujeitos em seus contextos de vida, é o campo de atuação de suas ações 9 .

A concepção de vulnerabilidade denota a multideterminação de sua gênese não estritamente condicionada à ausência ou precariedade no acesso à renda, mas atrelada também às fragilidades de vínculos afetivo-relacionais e desigualdade de acesso a bens e serviços públicos ${ }^{9}$. Não obstante as críticas em torno de sua indefinição conceitual 10,11, bastante amalgamada à noção de risco, a adoção de tal categoria, ao mesmo tempo em que buscou definir o objeto próprio e específico da assistência social, se contrapondo ao esvaziamento teórico-metodológico de suas entregas, aproximou-se de uma solução terminológica típica de correntes neoliberais e orientações de organismos internacionais 12,13. O que imprimiu nas ações da política um pressuposto ético-político individualizante, de focalização na parcela mais pauperizada da população 14 .

Diante da relevância de se analisar as direções que a proteção social vem tomando no contexto atual do Brasil, este artigo de reflexão crítica buscou compreender e interpretar, pelo método de revisão da literatura, as concepções de vulnerabilidade nas políticas não contributivas que compõem a seguridade social, produzidas nas duas últimas décadas. O objetivo foi problematizar as implicações da concepção de vulnerabilidade nas práticas públicas que visam à produção de cidadania, para compreender os tensionamentos e polarizações que pressionam a materialidade do modelo de Estado proposto pela Constituição Federal de 1988 e os rebatimentos destas concepções na população usuária dos serviços de saúde e assistência social.

O debate em torno da concepção de vulnerabilidade, hoje, pouco prolífico quando vinculado às ideias de cidadania presentes no modelo de proteção social estatal, mais do que meramente uma questão técnica, situada no campo semântico, busca trazer elementos de reflexão teórica que possam 
contribuir com o aprofundamento democrático no âmbito do acesso aos direitos de saúde e assistência social baseando-se no desvelamento dos rumos da seguridade social brasileira neste momento histórico. A proposta do presente artigo consiste, então, em discutir sobre as concepções de vulnerabilidade que figuram nas políticas públicas de saúde e assistência social, criando sentidos e influenciando práticas que impactam na cidadania engendrada pela seguridade social não contributiva.

\section{Métodos}

Este artigo de reflexão crítica, com abordagem compreensiva-interpretativa, utilizou uma revisão da literatura como método. Optamos por realizar consulta na biblioteca virtual de periódicos eletrônicos da Coordenação de Aperfeiçoamento de Pessoal de Nível Superior (Portal de Periódicos Capes), devido ao seu amplo acervo de documentos completos e gratuitos, que inclui importantes bases de busca para a saúde coletiva e assistência social.

Utilizamos os estudos que estavam integralmente disponíveis para o acesso público e sua seleção aconteceu entre agosto e novembro de 2016. Desenvolvemos o mapeamento de estudos em duas fases, descritas na Figura 1. Inicialmente, fizemos uma busca avançada no Portal de Periódicos Capes mediante o uso de termos situados em qualquer parte de todos os tipos de materiais produzidos em qualquer idioma. Com os descritores Vulnerabilidade AND Cidadania, utilizados sem aspas, admitimos a pesquisa para estudos produzidos em qualquer ano, o que resultou em 44 trabalhos, entre artigos, recursos textuais e teses.

Na segunda fase, realizamos uma busca avançada com o uso dos descritores Vulnerabilidade AND "Seguridade Social", em todos os tipos de materiais produzidos em qualquer data, resultando em um artigo e um recurso textual. $O$ recurso textual foi excluído por não conter a obra integralmente disponível para leitura. Do total de 45 trabalhos, 24 foram excluídos após a leitura dos títulos e resumos, por não tratarem do tema pesquisado. Não detectamos estudos duplicados em nenhuma das fases de busca. Com a leitura integral dos 21 trabalhos, cinco foram excluídos por não apresentarem contribuição teórica para discutirmos conceitos de vulnerabilidade. Não consideramos documentos institucionais como fontes autorais.

Adotamos o referencial analítico hermenêutico-dialético que, além de propiciar a compreensão de textos e falas inseridos em uma totalidade que explicita o componente social do conhecimento, enseja a ênfase na linguagem e na subjetividade para o estudo crítico de fenômenos complexos e contraditórios 15,16,17. A perspectiva de cidadania e políticas públicas sociais orientou, como totalidades de sentido, as interpretações críticas, baseadas na busca por aspectos contraditórios e/ou similares, que expressassem rupturas e/ou continuidades para a compreensão do sentido dos usos das concepções de vulnerabilidade nos discursos que implicam as políticas estudadas.

Para organizar os materiais encontrados, delineamos duas categorias operacionais com a leitura flutuante dos estudos. Com o referencial hermenêutico-dialético, construímos tais categorias considerando nossos preconceitos em relação à temática. A análise empreendida posteriormente pôde se valer de ideias disparadoras que provocaram estranhamento, favorecendo o processo de compreensão e crítica. Assim, a organização dos estudos levou em conta os aspectos expressos nas categorias operacionais: (1) contexto dos estudos (local e data de produção, área de conhecimento, temática abordada); (2) referências bibliográficas em comum. Após a realização da leitura pormenorizada dos trabalhos, definimos as seguintes categorias de análise para proceder à investigação: (1) concepções de vulnerabilidade em saúde e assistência social; (2) influências das concepções de vulnerabilidade nas práticas sociais.

\section{Resultados}

Os resultados mostram que não há vasta produção que contemple a temática específica desta pesquisa. Dos 46 estudos mapeados, apenas 16 tratam do conceito de vulnerabilidade ou da sua implicação no desenho de políticas públicas para a garantia de direitos à cidadania. 


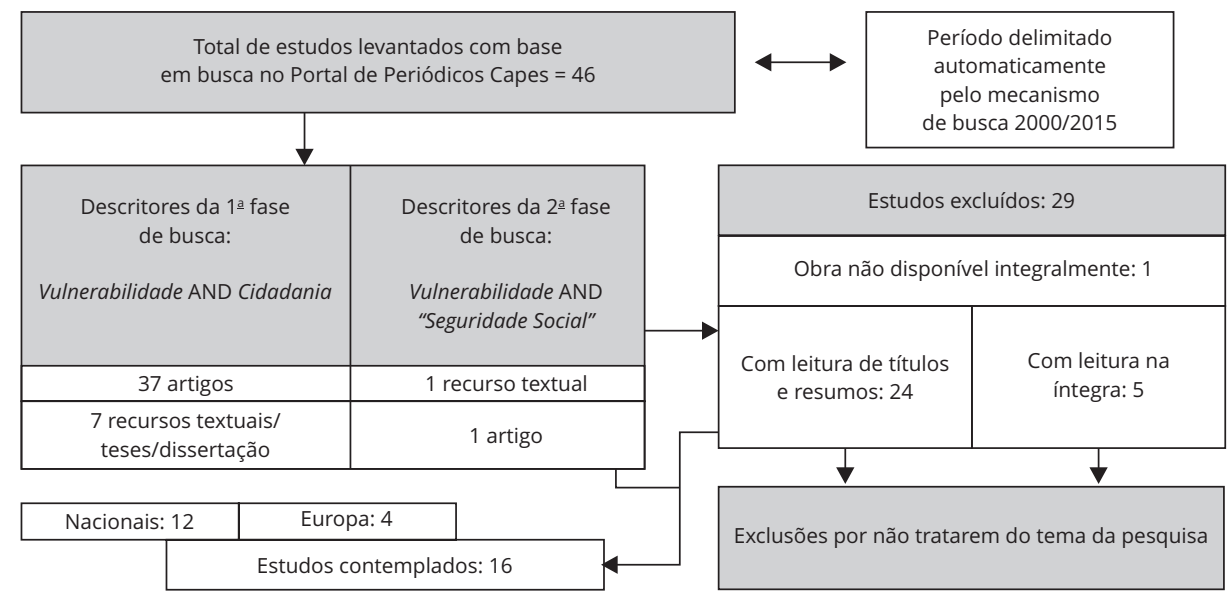

Das obras selecionadas, 12 foram produzidas no Brasil, uma na Espanha e três em Portugal, sendo que uma destas últimas pesquisou em uma cidade brasileira. O município foi lócus de pesquisa de 11 dos trabalhos selecionados; três estudos apresentaram enfoque nacional e dois abordaram o contexto internacional. O mecanismo de busca automaticamente levou a estudos cuja produção, recente, esteve concentrada entre os anos de 2000 e 2014.

Foram levantadas quatro teses, uma dissertação e dez artigos. Dos recursos textuais, um é editorial de revista científica portuguesa. Ciências sociais, psicologia e assistência social foram as áreas que mais retornaram artigos e teses, seguidas por saúde e educação. Bastante homogêneos no que tange à abordagem metodológica, 15 trabalhos trouxeram metodologia de estudo essencialmente qualitativa, já apenas um estudo utilizou abordagem quantitativa. Sobre contribuições teóricas, do grupo de 16 autores de referência comuns nos estudos levantados apenas um autor é citado, simultaneamente, nas áreas de saúde e assistência social.

Mesmo constatando heterogeneidade nas temáticas estudadas, realizamos um agrupamento com base nos assuntos centrais dos trabalhos, conforme se vê na Tabela 1. As áreas de conhecimento foram delimitadas pela natureza dos periódicos, pelo assunto focado nos trabalhos e por maior ou menor interface destes com as áreas de interesse deste estudo.

Destaca-se o número de artigos e teses sobre o ciclo de vida dos sujeitos, evidenciando-se os estudos que se debruçam sobre a temática do público jovem e adolescente, acompanhados pela abordagem das questões da velhice. Os oito trabalhos acerca do público adolescente estão situados em todas as áreas de conhecimento encontradas na busca e discorrem sobre saúde, doenças sexualmente transmissíveis (DST), violência e, em maior grau, sobre a mutualidade de influências entre políticas públicas para adolescentes/jovens e a produção de sentido sobre a sua vulnerabilidade 18,19,20,21,22,23,24,25. A despeito do crescimento da população idosa em vários países no mundo, inclusive no Brasil, apenas um estudo espanhol da área da educação buscou compreender a representação social da velhice para o público que se encontra neste quadrante populacional, na perspectiva de contribuir para aprofundar seus direitos de cidadania 26.

Foram agrupados os estudos das áreas de assistência social e ciências sociais que refletem sobre vulnerabilidade socioeconômica como elemento principal para a conformação das políticas de proteção social, diante das transformações no mundo do trabalho 27 , e também como demanda para as ações de inclusão produtiva no âmbito do Sistema Único de Assistência Social (SUAS) 28 - em processo de 


\section{Tabela 1}

Agrupamento dos estudos com base na temática central, área de conhecimento e autores em comum.

\begin{tabular}{lc}
\hline Temática & Estudos \\
\hline Saúde (Brasil e Portugal) & 2 \\
Saúde de adolescentes & 2 \\
Desastres & 1 \\
População de rua & 5 \\
Total & \\
Assistência social (Brasil e Espanha) & 6 \\
Adolescência, vulnerabilidade e políticas públicas & 1 \\
Vulnerabilidade econômica & 1 \\
Família & 1 \\
Velhice & 1 \\
Inclusão produtiva & 1 \\
SUAS & 11 \\
Total & 1 \\
\hline
\end{tabular}

SUAS: Sistema Único de Assistência Social.

consolidação ${ }^{29}$. O foco sobre desastres ambientais está presente nos trabalhos das ciências sociais que reúnem análises relativas às desigualdades sociais e seu impacto nos contextos vulnerabilizantes 30,31 . $\mathrm{O}$ viés social presente nesses textos diz respeito à ampliação do olhar sobre os diferentes riscos a que grupos populacionais estão submetidos, demandando ação do Estado para a garantia de sua qualidade de vida, segurança e cidadania. Perpassam pelo alerta do perigo de se individualizar a responsabilidade pela superação da situação de vulnerabilidade por meio do discurso da resiliência.

As discussões sobre atenção à população de rua e noções de família encontram-se isoladas, cada uma em um artigo. Nota-se a preocupação da área da saúde com os direitos da população de rua de forma ampliada. Ao se levar em consideração que a situação de rua decorre de fragilidades de diferentes matizes 32, o estudo encontrado nos chama a atenção para o desafio da intersetorialidade no atendimento e reconhecimento da especificidade das demandas dessa população. Já as noções de família que perpassam por programas de inclusão social oferecem material para análise de suas contribuições na superação ou manutenção de vulnerabilidades do público atendido, associadas, especialmente, à perspectiva de gênero 33 . Similarmente ao estudo que tratou sobre população de rua, nesse sobre noções de família veio à tona a dimensão transversal da vulnerabilidade como fundamento para a adoção de soluções intersetoriais.

\section{Discussão}

Para adentrar na discussão sobre conceitos, voltamos ao significado da palavra vulnerabilidade. O horizonte neste momento é debater os nexos semânticos, ressaltar as discrepâncias e os elementos compartilhados ou não pelas matrizes discursivas que manejam conceituações sobre vulnerabilidade. Posteriormente, os distanciamentos e aproximações entre os conceitos de vulnerabilidade nas áreas da saúde e assistência social passam a direcionar a análise para compreendermos como os conceitos influenciam o imaginário dos cidadãos e as práticas de proteção social estatal.

Com o exercício etimológico resgatamos que a conexão dos vocábulos em latim vulnerare, que significa ferir, lesar, prejudicar 11,34,35,36,37,38, e 'bülis - suscetível a 36 - teria dado origem à palavra vulnerabilidade. Conformado na matriz discursiva da Bioética, o conceito de vulnerabilidade como condição inerente ao ser humano 34, naturalmente necessitado de ajuda 39, diz do estado de ser/estar em perigo ou exposto a potenciais danos em razão de uma fragilidade atrelada à existência individual, eivada de contradições 34,40 . 
O ser humano vulnerável, por outro lado, é aquele que, conforme conceito compartilhado pelas áreas da saúde e assistência social, não necessariamente sofrerá danos, mas está a eles mais suscetível uma vez que possui desvantagens para a mobilidade social 21,24,32, não alcançando patamares mais elevados de qualidade de vida em sociedade em função de sua cidadania fragilizada 34,35. Assim, ao mesmo tempo, o ser humano vulnerável pode possuir ou ser apoiado para criar as capacidades necessárias para a mudança de sua condição. É com base nessa última afirmação que concordamos que não se trata, a vulnerabilidade, apenas de uma condição natural que não permite contestações. Isso porque percebemos que o estado de vulnerabilidade associa situações e contextos individuais e, sobretudo, coletivos.

Concepções menos centradas nos sujeitos como autores de sua própria vulnerabilidade são aceitas no bojo das teorias que defendem que o ser humano desenvolve capacidades e adquire ativos 24 - tidos como os meios internos e subjetivos de lidar com adversidades - a partir dos aportes e condições objetivas e materiais que estiverem disponibilizadas em seu contexto de vida. Do contrário, o que se constata, são situações de desigualdade, que marcam a diferenciação no usufruto de direitos por parte dos cidadãos, da mesma forma que tensionam as políticas sociais.

\section{Vulnerabilidade na saúde}

Em saúde, a utilização do termo vulnerabilidade começou no início dos anos 1980, com os estudos sobre a síndrome da imunodeficiência adquirida (aids) 19,40,41,42, compartilhando conceituações da área dos Direitos Humanos. Foram as características da evolução da epidemia, como a mudança no perfil das pessoas atingidas e variáveis socioeconômicas, que trouxeram à tona novas associações ao contexto da infecção, exigindo a redefinição das ideias individualizantes até então vigentes sobre os "grupos de risco" 40,41,42. A adoção do conceito de vulnerabilidade, em substituição ao de grupo de risco, aconteceu nesse processo, indicando a ampliação das chances e formas de acometimento pela doença pela totalidade da população 19,40,41,42.

Em contraponto à ideia de "Sociedade de Risco", que Ulrich Beck cunhou após o acidente nuclear de Chernobyl, Ucrânia, considerando-se que o risco expande de forma indistinta pelas sociedades $30,31,43,44,45$, a ecologia política surgiu como a corrente que discute conflitos socioambientais sob a ótica da desigualdade social - aqui tomada pela desigualdade de poder decisório e expulsão de populações economicamente desfavorecidas para as periferias das cidades - bem como sua exposição a contaminações e poluição. Com o elemento da vulnerabilidade sob perspectiva, o estudo dos conflitos ambientais passou a reconhecer que o aspecto social deve estar presente quando se trata de riscos, visto que a propensão de uma população ao risco sofre determinações da estrutura desigual de concentração de poder na sociedade 31,46 .

Com base nas contribuições dos trabalhos sobre desastres ambientais observamos que a guinada conceitual em direção à resiliência, tida como a habilidade e capacidade individual de enfrentar eventos vulnerabilizantes 31,43,46, reacende a preocupação acerca de uma gramática que responsabiliza os indivíduos pela garantia de não exposição de si e de outros a situações de vulnerabilidade. Coloca-os como agentes de reparação da situação de vulnerabilidade vivenciada em oposição ao estímulo a uma participação popular efetiva, que rompa processos subalternizantes 29,47,48 e socialmente injustos.

Quando refletimos sobre justiça social não é possível desconsiderar o contexto de vida dos sujeitos e como tais contextos podem contornar suas formas de expressividade, exercendo influências sobre as maneiras como se posicionam na sociedade e como se enxergam. A omissão e/ou o recuo do poder público em seu papel de proteção social cria ciclos de reprodução de situações de opressão, não só no sentido da desigualdade no acesso a políticas e serviços, mas de cerceamento da livre expressão e lutas dos sujeitos, o que esconde a dimensão coletiva da vivência das populações em contextos de produção de vulnerabilidades.

A saúde reconhece a preponderância das conjunturas macrossociais sem desconsiderar a dimensão pessoal requisitada para o enfrentamento das situações vulnerabilizantes. Tal olhar não se distancia de uma acepção mais abrangente em relação a contextos desiguais e injustos socialmente, porquanto refina a importância da capacidade de elaboração e interesse dos sujeitos para a incorporação dessa temática em seu dia a dia 49. 
Mais simplório do que considerar apenas o aspecto individual na indução de situações de vulnerabilidade, incorrendo na equivocada tendência de culpabilização dos sujeitos 27 , é abandonar por completo a dimensão pessoal e subjetiva do indivíduo no traçado de suas decisões. Interpelados por seu contexto societário, os cidadãos não podem se desvencilhar das contingências de sua existência humana 39 . É nessa contradição que reside o desafio de perceber o quão restritivos ou extensivos são os efeitos na produção de cidadania causados por conceituações incorporadas às políticas públicas de seguridade social não contributiva.

Contrariamente a qualquer posição radical ou binária, destacamos a validade da análise sobre vulnerabilidade valendo-se da associação de variáveis de cunho individual, social e programático/ institucional que se inter-relacionam $33,46,49$ por meio de seus limites imprecisos e permeáveis 50 . Esse processo favorece compreensões menos reducionistas, norteando políticas mais condizentes com a realidade. A conjugação de componentes relacionados ao tipo das informações recebidas pelos sujeitos, aos recursos e oportunidades para a obtenção e manuseio destas informações e às maneiras planejadas e democráticas de se potencializar tais recursos, permite alcançar a feição sintética do conceito de vulnerabilidade que, em saúde, não pretende superar a feição analítica do conceito de risco, ao passo que dialogam e se complementam em suas singularidades, interesses e limites, vinculando-se a diferentes referenciais ético-políticos 49 .

\section{Vulnerabilidade na assistência social}

Conceitos sobre vulnerabilidade surgem na área da saúde reordenando as práticas de prevenção e promoção para um enfoque mais contextualizado e atento ao aspecto social. De modo semelhante, na assistência, o conceito de vulnerabilidade é adjetivado pelo termo social, que indica a evolução do entendimento acerca das privações e desigualdades ocasionadas pela pobreza 12,13,29,43,51.

A partir dos anos 1990, inicia um esforço teórico para a compreensão do fenômeno da pobreza e suas consequências para além do enfoque nas variáveis puramente econômicas 13,28,29. Essa é a tônica levada a cabo por organismos internacionais, incorporando o conceito de vulnerabilidade, de cariz mais amplo, às políticas sociais brasileiras, reorientando a política pública de assistência social 12 .

As imbricações entre os conceitos de risco e vulnerabilidade no campo da assistência social 11,12,13,43 levam a concepções que tomam desde a dimensão mais individual do primeiro sobre o segundo 13 , passando pela assunção daquele como a condição da frágil sociedade contemporânea e deste como a condição dos indivíduos inseridos nesta sociedade 11, culminando por atrelar a situação de vulnerabilidade dos sujeitos a um certo risco 43 . Ainda que as discussões empreendidas prezem por distinções conceituais, temos de admitir que o termo vulnerabilidade, no escopo da assistência social, se destaca pela aptidão com que engloba situações entre a iminência de um risco e a desvinculação ou desfiliação social, de fato $18,27,28,47,51,52$.

Muito embora possamos considerar que a vulnerabilidade se instale, em maior grau, nas populações pobres, nas sociedades capitalistas contemporâneas, em que as relações sociais se desenvolvem por modos marcadamente complexos, a questão econômica é relevante, porém não determinante. Devido ao precário acesso à renda, os sujeitos ficam privados ou acessam com mais dificuldade os meios de superação das vulnerabilidades vivenciadas, sejam tais meios materiais ou capacidades impalpáveis, como a autonomia, a liberdade, o autorrespeito 43,51. É nesse sentido que se torna possível associar a vulnerabilidade à precariedade no acesso à garantia de direitos e proteção social 29,43, caracterizando a ocorrência de incertezas e inseguranças e o frágil ou nulo acesso a serviços e recursos para a manutenção da vida com qualidade.

\section{Influências nas práticas sociais}

Derivada da expressão latina sine cura - sem cuidados, garantido, que originou securitas/seguritate segurança 53, a palavra seguridade designa, no Brasil, um sistema de proteção social composto por ações do poder público, da sociedade e pelo aparato legal-normativo que pretendem assegurar direitos de cidadania aos indivíduos 54 . Ao passo que inaugura um processo inovador para implementar as políticas sociais que compõem o seu tripé, o sistema de seguridade social também atua na manutenção do modo de produção capitalista por meio das bases para a reprodução da força de trabalho 6 . 
A seguridade social brasileira teve incluídas em seu escopo a saúde e a assistência social em uma linha programática vinculada à proteção social redistributiva, diferentemente da lógica do seguro em que foi assentada a previdência social 16,43. No entanto, e ainda que tal incorporação tenha acontecido em 1988, os desafios de consolidação de uma efetiva proteção social por meio do Estado são bastante atuais. Um desses desafios requisita que a assistência social transite da esfera das carências para a do direito de cidadania, rompendo com o viés clientelista e benemerente que outrora a caracterizou 29.

Reconhecida por atuar no contraditório campo da reprodução social da força de trabalho e atenuação de conflitos sociais 14,48, a política pública de assistência social tem seus rumos impactados pelas disputas que acontecem no plano ideológico e material quanto a diferentes projetos de Estado mais enxuto ou mais alargado em suas funções interventivas 27 . Afirma-se que as ações dessa política, ao procurarem incidir, especialmente, na parcela de cidadãos inseridos precariamente ou alijados do mundo do trabalho, instalam-se no âmbito do enfrentamento das diversas vulnerabilidades oriundas do sistema capitalista, que reifica relações sociais e acirra desigualdades 28 .

Garantir direitos de cidadania, nesse prisma, tem implicações de um ideário estigmatizante, socialmente construído, que, além de moldar a opinião pública, influencia diretamente a formação e o trabalho de profissionais das áreas de saúde e assistência social. Longe de ser uma questão restrita ao Brasil, a discussão que busca orientar o papel do Estado, nos momentos em que o capitalismo mostra seu esgotamento (muito embora tal esgotamento em crises cíclicas seja algo inerente ao sistema), foi intensificada na década de 1990 em países como França e Estados Unidos, onde, respectivamente, disputaram por supremacia os projetos de responsabilidade estatal pela proteção social e o encolhimento do Estado diante da convicção do incentivo ao ócio causado pelas políticas de bem-estar social 27.

A partir de 2010, a reforma do sistema de saúde norte-americano, considerando a injustiça na distribuição de serviços de saúde nos Estados Unidos 55, sem perder de vista a predominância da lógica mercantil, seguiu, não sem críticas e ambiguidades, na tentativa de expandir a cobertura de saúde aos cidadãos por meio da obrigatoriedade do contrato de planos privados de saúde, tornados mais acessíveis. A Lei Federal de Proteção ao Paciente e da Saúde Acessível (Patient Protection and Affordable Care $A c t$ ), sancionada em 2010, pelo governo democrata, previu ainda a ampliação dos programas públicos de saúde sem criar uma cobertura de saúde universal 56, como ocorre na França e no Brasil 57, não obstante a "seletividade não assumida" 58 do Sistema Único de Saúde (SUS) brasileiro.

A atual política pública de assistência social brasileira foi antecedida por um longo período de “cidadania regulada" 59,60 em um Estado que, para não incorrermos em uma "analítica da falta" 59, desenvolveu-se como um Estado de Bem-estar Social peculiar às características do país de capitalismo tardio e governo autoritário 61. Após a sua inserção no tripé da seguridade social brasileira e às voltas com as determinações dos organismos internacionais e pressões populares e políticas por um país responsável fiscalmente, a conformação da assistência social como política pública acaba por se encontrar vulnerável ${ }^{62}$. A vulnerabilidade que a atinge pode minar os recursos para a sua consolidação, financiamento e legitimação na sociedade, de forma a prejudicar o alcance de seus princípios e objetivos.

A característica de sujeito vulnerável, que necessita ter fortalecidas suas funções protetivas, na linha das atuais diretivas dos organismos internacionais 12 , elege a família como sujeito alvo das políticas públicas de seguridade social. A centralidade que tal instituição obteve nas políticas públicas recentes, haja vista a expansão da cobertura do SUS a partir da implantação da Estratégia Saúde da Família (ESF) na atenção primária e a adoção da matricialidade sociofamiliar como eixo estruturante do SUAS, não denuncia o ineditismo do olhar das políticas para a família, uma vez que sua entrada na agenda pública estatal remete aos primórdios do desenho da seguridade social brasileira.

Essa instituição dinâmica, espaço de socialização primária, cuidado, reprodução social, mas também de violação de direitos, que no decurso da história estabelece influências mútuas com a sociedade, adquire a posição dúbia de alvo e parceira para a consecução dos objetivos das políticas públicas sociais. Sua eleição como sujeito de direitos incorpóreo 48 da política pública de assistência social colocou em questão a produção de cidadania pelo sistema de seguridade social e a autonomia do grupo familiar com base em aspectos que pendem ora para a superação do modo segmentado de atenção da política de assistência social, para melhorar a forma de enfrentar processos de desproteção, e ora entre a desresponsabilização do Estado e sobrecarga para as famílias quanto à resolução das situações de vulnerabilidade que vivenciam 48,63,64,65. 
A perspectiva familista 65 , muitas vezes encoberta nas políticas sociais, atravessa-as pautando discursos e práticas psicologizantes 48 . Não é revelada a dimensão coletiva das vulnerabilidades que acometem os sujeitos em seus contextos, ao tempo em que a família é chamada para exercer protagonismo na proteção de seus membros. Com isso, a função de proteção e cuidado, que recai com maior intensidade sobre a mulher, somada aos parcos recursos para o seu desempenho, é acrescida pela sobrecarga simbólica de incapacidade frente às dificuldades impostas pelo capital. Tal situação acarreta maiores dificuldades do exercício protetivo e exacerba desigualdades de gênero. Não por outro motivo, o cuidado, a proteção e a autonomia de membros adolescentes e idosos ficam ainda mais controversos. A condição específica desses membros demanda não só apoio para a capacidade protetiva das famílias, como também a corresponsabilização do Estado para a proteção dos familiares em ciclos de vida singulares 24 .

Sentimentos como os de desqualificação frente aos longos períodos de inserção em programas assistenciais e não inserção no mercado de trabalho; de impotência para o enfrentamento das adversidades, ou de incompetência por não compartilhamento de saberes dominantes, ainda que se configurem em situações vulnerabilizantes, com tendência a provocar fragilização de vínculos sociais e isolamento, não devem ser justificativa para direcionar práticas disciplinadoras e moralizantes sobre o público das políticas de saúde e assistência social 18,21,27,28,29. O reconhecimento das potencialidades dos cidadãos como sujeitos de direitos e a necessidade de se descortinar as implicações estruturais que os colocam em situação de vulnerabilidade, requerendo organização para a exigência ao poder público de acesso mais igualitário a oportunidades, fazem parte de uma conduta que pressupõe esforço constante.

Apoiar o desenvolvimento de capacidades humanas 66 , individualmente, nas famílias e no território, pressupõe adesão a uma vertente protetiva que admite a existência de ativos e o benefício de fortalecê-los para o enfrentamento de situações de vulnerabilidade pelos sujeitos 46,67. Entretanto, em meio a discordâncias teóricas acerca do grau de mercantilização imbuído na concepção de ativos 43, a importância de considerá-los não minimiza a inevitabilidade de se problematizar que o acesso a uma estrutura de oportunidades depende, sobremaneira, de trade offs manejados na esfera pública e da efetiva participação popular nas tomadas de decisão.

O conceito de vulnerabilidade observado nas produções teóricas sobre as políticas públicas de saúde e assistência social evidenciam a conformação de um conceito em processo, mas, sobretudo, indicam a multiplicidade de fatores que determinam o fenômeno. $\mathrm{O}$ olhar para a integralidade dos sujeitos em situação de vulnerabilidade nada mais faz do que se alinhar à constatação de que estes sujeitos possuem demandas e necessidades de diversas ordens, possuem capacidades e se encontram em um estado de suscetibilidade a um risco devido à vivência em contextos de desigualdade e injustiça social. Assim, justiça e equidade na distribuição de riquezas, poder decisório e na estrutura de oportunidades são o horizonte para se romper com a ordem capitalista e buscar uma nova ordem societária, livre de discriminações e subalternizações.

Vulnerabilidade e capacidade estão inseridas em um igual processo de luta por superação ${ }^{42}$, ou seja, na vulnerabilidade reside o germe para o seu próprio enfrentamento. Dessa forma, será exigida do Estado, por meio dos serviços públicos, maior aproximação possível com o cotidiano da vida das pessoas, pois é nele que riscos e vulnerabilidades se constituem 9 .

A responsabilidade na garantia de direitos pelo poder público e a ativa participação popular são elementos essenciais para a defesa e usufruto da cidadania pela parcela da população que vivencia situações de vulnerabilidade. Mas é imperativo retornar ao importante e estratégico espaço ocupado por gestores e profissionais do SUS e do SUAS em qualquer das três esferas governamentais. Formados por sua história e convicções pessoais, esses trabalhadores imprimem sua digital no curso da consolidação dos direitos de cidadania previstos no âmbito da seguridade social brasileira. Os arranjos intersetoriais, a interação interdisciplinar e o respeito à liberdade dos sujeitos de direitos, usuários das políticas, são práticas que têm grande potencial para eliminar relações assimétricas 46 que insistem em vigorar nas instituições onde as vulnerabilidades devem ser suprimidas ao invés de reforçadas. 


\section{Considerações finais}

O termo vulnerabilidade foi inserido no léxico das políticas públicas brasileiras de seguridade social não contributiva orientando a abrangência de suas ofertas. Todavia, conforme os resultados deste estudo, a imprecisão conceitual do termo ainda permanece, demandando trabalhos mais aprofundados. Ainda que exista uma considerável produção científica sobre vulnerabilidade ao longo das duas últimas décadas, pouco se estudou sobre a vinculação dos diferentes conceitos que a palavra vulnerabilidade pode admitir e sua relação com a produção de cidadania no âmbito das políticas públicas de saúde e assistência social.

A reflexão crítica com base na revisão da literatura sobre vulnerabilidade, seguridade social e cidadania nas áreas da saúde e da assistência social revelou pontos de convergência bastante sinérgicos no que diz respeito à ideia de um conceito que representa as múltiplas determinações que incidem sobre os contextos de cidadãos que vivenciam frágil ou nulo acesso a direitos.

A compreensão e o uso do vocábulo vulnerabilidade evoluíram com a nova forma de lidar com a epidemia da aids, nos anos 1980. Passou-se a admitir que a suscetibilidade de contágio devia-se mais a um conjunto de fatores econômicos, sociais e culturais do que ao comportamento individual. Considerar fatores que transcendem o biológico, quando se fala de sujeitos em vulnerabilidade, foi a tônica observada nos estudos levantados na área da saúde. Seja em relação ao meio ambiente, a adolescentes ou à população em situação de rua, podemos considerar que a produção de cidadania e formas saudáveis de viver estão atreladas à justa distribuição de poder e conhecimento, haja vista a premência do olhar para os sujeitos em sua integralidade.

Nos estudos da área da assistência social, ficou evidente que a pobreza não explica a vulnerabilidade, mas é o fenômeno que ocasionou o seu apuramento conceitual, mesmo que tal tarefa não tenha resultado em concepções mais nítidas. Valendo-se da impossibilidade de restringir a gênese de processos excludentes e subalternizantes à questão da ausência ou insuficiência de renda, a vulnerabilidade vem se delineando como categoria que equaciona mais amplamente a problemática, admitindo condutas intersetoriais entre as políticas públicas. Contudo, a incorporação das vulnerabilidades no escopo da atuação da política pública de assistência social, no sentido de superá-las, é um processo que revela contradições, pois, partindo de um direcionamento colocado pela cartilha dos organismos internacionais, pode dirimir ou mesmo intensificar a vulnerabilização dos sujeitos. Sendo assim, é justificável todo o esforço de compreensão da influência que o conceito de vulnerabilidade exerce na formulação das políticas, nas práticas profissionais, na sociedade e na representação que os usuários têm de si mesmos.

Ainda que o termo vulnerabilidade carregue imprecisões frutificadas pelo processo de construção conceitual em que se encontra, há avanços na discussão da realidade dinâmica e multideterminada. A acepção da vulnerabilidade como parâmetro de reflexão e atuação implica o reconhecimento da concomitância de fatores éticos, políticos e técnicos contornando a incidência de riscos nos territórios e a capacidade humana para o seu enfrentamento.

Esperamos ter contribuído para suscitar as necessárias reflexões sobre como conceitos diversos se moldam ao longo da história e são inseridos no rol de objetos das políticas públicas sociais, podendo definir seus rumos ou ficarem esvaziados de sentido. Observamos que é fundamental a ampliação deste debate, uma vez que os conceitos presentes nas políticas públicas nunca são inócuos, mas, se incompreendidos, podem esconder projetos contrários ao aprofundamento democrático e cidadão dos sujeitos de direitos. 


\section{Colaboradores}

M. E. Carmo foi responsável pela concepção, análise e interpretação dos dados, redação do artigo, e responsável também por todos os aspectos do trabalho na garantia da exatidão e integridade de qualquer parte da obra. F. L. Guizardi colaborou na concepção, revisão crítica relevante do conteúdo intelectual e aprovação final da versão a ser publicada.

\section{Agradecimentos}

Agradecemos à Hérika Eustáquia do Carmo pela revisão técnica. Agradecemos à Fernanda Severo, Kênia Figueiredo e Luciana Sepúlveda pelas contribuições.

\section{Referências}

1. Behring ER. Brasil em contra reforma: desestruturação do Estado e perda de direitos. São Paulo: Cortez Editora; 2003.

2. Simionatto I. Reforma do Estado ou modernização conservadora? O retrocesso das políticas sociais públicas nos países do Mercosul. http://www.artnet.com.br/gramsci/arquiv 150.htm (acessado em 20/Nov/2016).

3. Fleury S. Contra-reforma e resistência. In: Costa L, Rocha D, Bernardo M, organizadoras. A era FHC e o governo Lula: transição? Brasília: Instituto de Estudos Socioeconômicos; 2004. p. 121-50.

4. Iamamoto MV. O serviço social na contemporaneidade: trabalho e formação profissional. São Paulo: Cortez Editora; 2000.

5. Fleury S. A seguridade social inconclusa. In: Costa L, Rocha D, Bernardo M, organizadoras. A era FHC e o governo Lula: transição? Brasília: Instituto de Estudos Socioeconômicos; 2004. p. 107-20.

6. Teixeira A. Do seguro à seguridade: a metamorfose inconclusa do sistema previdenciário brasileiro. Rio de Janeiro: Instituto de Economia, Universidade Federal do Rio de Janeiro; 1990. (Texto para Discussão, 249).

7. Brasil. Lei no 8.080 , de 19 de setembro de 1990. Dispõe sobre as condições para a promoção, proteção e recuperação da Saúde, a organização e o funcionamento dos serviços correspondentes e dá outras providências. Diário Oficial da União 1990; 20 set.

8. Buss PM, Pellegrini Filho A. A saúde e seus determinantes sociais. Physis (Rio J.) 2007; 17:77-93.

9. Secretaria Nacional de Assistência Social, Ministério do Desenvolvimento Social e Combate à Fome. Resolução do Conselho Nacional de Assistência Social - CNAS no 145, de 15 de outubro de 2004. Aprova a Política Nacional de Assistência Social - PNAS. Brasília: Ministério do Desenvolvimento Social e Combate à Fome; 2009.

10. Oliveira LMA. Vulnerabilidade social e situações de risco. http://www.mp.rn.gov.br/ portal/inicio/pessoa-com-deficiencia/pessoacom-deficiencia-material-de-apoio/2037-vul nerabilidade-social-e-situacoes-de-risco-1? path (acessado em 13/Jun/2016).

11. Janczura R. Risco ou vulnerabilidade social? Textos Contextos (Porto Alegre) 2012; 11:301-8.

12. Alvarenga MS. Risco e vulnerabilidade: razões e implicações para o uso na Política Nacional de Assistência Social [Dissertação de Mestrado]. Vitória: Programa de Pós-graduação em Política Social, Universidade Federal do Espírito Santo; 2012.

13. Monteiro SRRP. O marco conceitual da vulnerabilidade social. Sociedade em Debate 2011; 17:29-40.

14. Paulo Netto J. Capitalismo monopolista e serviço social. São Paulo: Cortez Editora; 1992.

15. Minayo MCS. O desafio do conhecimento: pesquisa qualitativa em saúde. 14ạ Ed. São Paulo: Editora Hucitec; 2014. 
16. Cardoso MF, Santos ACB, Alloufa JML. Sujeito, linguagem, ideologia, mundo: técnica hermenêutico-dialética para análise de dados qualitativos de estudos críticos em administração. Revista de Administração FACES Journal 2015; 14:74-93.

17. Stein E. Dialética e hermenêutica: uma controvérsia sobre o método em filosofia. Síntese Revista de Filosofia 1983; 10:21-48.

18. Marques EMM. A transformação dos esquemas de motivação, percepção e de ação que compõem o habitus de jovens em risco de desinserção social [Tese de Doutorado]. Porto: Faculdade de Letras, Universidade do Porto; 2012.

19. Paiva V, Peres C, Blessa C. Jovens e adolescentes em tempos de aids: reflexões sobre uma década de trabalho de prevenção. Psicol USP 2002; 13:55-78.

20. Frezza M, Maraschin C, Santos NS. Juventude como problema de políticas públicas. Psicol Soc 2009; 21:313-23.

21. Guareschi NMF, Reis CD, Huning SM, Bertuzzi LD. Intervenção na condição de vulnerabilidade social: um estudo sobre a produção de sentidos com adolescentes do programa do trabalho educativo. Estud Pesqui Psicol 2007; 7:20-30.

22. Raposo C. A Política de Atenção Integral à Saúde do Adolescente e Jovem: uma perspectiva de garantia de direito à saúde? Em Pauta: Teoria Social e Realidade Contemporânea 2009; 6:117-38.

23. Rocha PR. Estação cidadania - uma experiência no atendimento de crianças e adolescentes em situação de risco. Rev Ter Ocup 2006; 17:37-41.

24. Rocha SR. Possibilidades e limites no enfrentamento da vulnerabilidade social juvenil: a experiência do Programa Agente Jovem em Porto Alegre [Tese de Doutorado]. Porto Alegre: Programa de Pós-graduação em Serviço Social, Pontifícia Universidade Católica do Rio Grande do Sul; 2007.

25. Lopes RE, Adorno RCF, Malfitano APS, Takeiti BA, Silva CR, Borba PLO. Juventude pobre, violência e cidadania. Saúde Soc 2008; 17:63-76.

26. Sanhueza J. Estereótipos sociais sobre a velhice em estudantes idosos: um estudo de caso. Revista Internacional de Educación para la Justicia Social 2014; 3:217-29.

27. Kowarick L. Sobre a vulnerabilidade socioeconômica e civil: Estados Unidos, França e Brasil. Rev Bras Ciênc Soc 2003; 18:61-86.

28. Nunes NMSG. Inserção produtiva e assistência social: caminhos para a inclusão? [Dissertação de Mestrado]. Porto Alegre: Programa de Pós-graduação em Serviço Social, Pontifícia Universidade Católica do Rio Grande do Sul; 2012.

29. Lajús MLS. Sistema Único de Assistência Social: um difícil caminho rumo à conquista da cidadania [Tese de Doutorado]. Porto Alegre: Programa de Pós-graduação em Serviço Social, Pontifícia Universidade Católica do Rio Grande do Sul; 2010.
30. Mendes JM, Tavares AO. Risco, vulnerabilidade social e cidadania. Revista Crítica de Ciências Sociais 2011; (93):5-8.

31. Fernandes LO. Complexidade, incertezas e vulnerabilidades: estudo de áreas contaminadas habitadas em Portugal e no Brasil [Tese de Doutorado]. Coimbra: Programa de Doutoramento em Governação, Conhecimento e Inovação, Universidade de Coimbra; 2011.

32. Fiorati RC, Carretta RYD, Panúncio-Pinto MP, Kebbe LM, Lobato BC. População em vulnerabilidade, intersetorialidade e cidadania: articulando saberes e ações. Saúde Soc 2014; 23:1458-70.

33. Meyer DE, Klein C, Fernandes PL. Noções de família em políticas de "inclusão social" no Brasil contemporâneo. Revista Estudos Feministas 2012; 20:433-49.

34. Morais IM. Vulnerabilidade do doente versus autonomia individual. Rev Bras Saúde Matern Infant 2010; 10 Suppl 2:S331-6.

35. Almeida LD. Suscetibilidade: novo sentido para a vulnerabilidade. Rev Bioét 2010; 18:537-48.

36. Pereira Júnior JRBS. Vulnerabilidade. https:// wikiglaw.fd.uc.pt/mediawiki/index.php/ Vulnerabilidade (acessado em 13/Jun/2016).

37. Neves MP. Sentidos da vulnerabilidade: característica, condição, princípio. Revista Brasileira de Bioética 2006; 2:157-72.

38. Tedesco S, Liberman F. O que fazemos quando falamos em vulnerabilidade? Mundo Saúde 2008; 32:254-60.

39. Nogueira RP. Saúde e liberdade na era das doenças crônicas. In: Nogueira RP, Santana JP, Rodrigues VA, Ramos ZVO, organizadores. Estudos e análises, 2. Brasília: Núcleo de Estidos em Saúde Pública, Universidade de Brasília/Observatório de Recursos Humanos em Saúde do Brasil/Núcleo de Estudos sobre Bioética e Diplomacia em Saúde, Fundação Oswaldo Cruz; 2015. p. 211-25.

40. Corrêa CS. Violência urbana e vulnerabilidades: o discurso dos jovens e as notícias de jornais [Dissertação de Mestardo]. Rio de Janeiro: Programa de Pós-graduação em Psicologia Clínica, Pontifícia Universidade Católica do Rio de Janeiro; 2010.

41. Costa RRO, Bosco Filho J, Silva MBM, Lourenço da Silva PFS, Medeiros SM. Vulnerabilidade social e saúde: interfaces do cuidado e estratégias de enfrentamento na atenção básica. http://apps.cofen.gov.br/cbcenf/ sistemainscricoes/arquivosTrabalhos/I37712. E10.T7978.D6AP. Pdf (acessado em 13/Jun/ 2016).

42. Sánchez AIM, Bertolozzi MR. Pode o conceito de vulnerabilidade apoiar a construção do conhecimento em Saúde Coletiva? Ciênc Saúde Coletiva 2007; 12:319-24.

43. Sposati A. Modelo brasileiro de proteção social não contributiva: concepções fundantes. In: Sposati A, organizador. Concepção e gestão da proteção social não contributiva no Brasil. Brasília: Ministério do Desenvolvimento Social e Combate à Fome/Organização das Nações Unidas para a Educação, a Ciência e a Cultura; 2009. p. 13-55. 
44. Porto MFS. Uma ecologia política dos riscos: princípios para integrarmos o local e o global na promoção da saúde e da justiça ambiental. 2a Ed. Rio de Janeiro: Editora Fiocruz; 2012.

45. Robalinho M. Para além dos riscos: uma análise do livro Sociedade de Risco. RECIIS (Online) 2014; 8:53-5.

46. Bronzo C. Vulnerabilidade, empoderamento e metodologias centradas na família: conexões e uma experiência para reflexão. In: Sposati A, organizador. Concepção e gestão da proteção social não contributiva no Brasil. Brasília: Ministério do Desenvolvimento Social e Combate à Fome/Organização das Nações Unidas para a Educação, a Ciência e a Cultura; 2009. p. 171-201.

47. Daros RF. Implicâncias e implicações de uma trabalhadora social: a participação social do PAC Favelas - RJ em análise [Dissertação de Mestrado]. Niterói: Programa de Pós-graduação em Psicologia, Universidade Federal Fluminense; 2016.

48. Paiva BA, Carraro D, Rocha MF. Cartografia teórico-metodológica no estudo da proteção socioassistencial básica do SUAS. In: Paiva BA, organizadora. Sistema Único de Assistência Social em perspectiva: direitos, política pública e superexploração. São Paulo: Editora Veras; 2014. p. 27-74.

49. Ayres JRCM, França Junior I, Calazans GJ, Saletti Filho HC. O conceito de vulnerabilidade e as práticas de saúde: novas perspectivas e desafios. In: Czeresnia D, Freitas CM, organizadores. Promoção da saúde: conceitos, reflexões, tendências. Rio de Janeiro: Editora Fiocruz; 2003. p. 117-39.

50 Almeida Filho N. Transdisciplinaridade e o paradigma pós-disciplinar na saúde. Saúde Soc 2005; 14:30-50.

51. Magalhães EP. Combatendo a pobreza e enfrentando as vulnerabilidades: desafios para a articulação entre o Programa Bolsa Família e a Proteção Social Básica. In: Sposati A, organizador. Concepção e gestão da proteção social não contributiva no Brasil. Brasília: Ministério do Desenvolvimento Social e Combate à Fome/ Organização das Nações Unidas para a Educação, a Ciência e a Cultura; 2009. p. 401-23.

52. Castel R. A dinâmica dos processos de marginalização: da vulnerabilidade à desfiliação. Caderno CRH 1997; 10:19-40.

53. Origem da Palavra. Segurança. http://origem dapalavra.com.br/site/palavras/seguranca/ (acessado em 05/Fev/2017).

54. Boschetti I. Seguridade social: a armadilha dos conceitos. https://www.acade mia.edu/8038311/Seguridade_Social_a_ Armadilha_dos_Conceitos (acessado em 05/ Jan/2017).

55. Dworkin R. A virtude soberana: a teoria e a prática da igualdade. 2a Ed. São Paulo: Editora Martins Fontes; 2011.

56. Baliardo R, Melo JO. Obamacare é constitucional, diz Suprema Corte dos EUA. http:// www.conjur.com.br/2012-jun-28/suprema-corte-eua-mantem-lei-reforma-sistemasaude? utm_source = twitterfeed\&utm medium=twitter (acessado em 12/Fev/2017).
57. Anjos JN. Regulação no setor da saúde: análise de direito comparado - Portugal, Reino Unido, França e Espanha. Publicações CEDIPRE On-line2015;26.http://www.fd.uc.pt/cedipre/ publicacoes/online/public_26.pdf.

58. Vianna MLTW. O processo de americanização da proteção social para os brasileiros. In: Vianna MLTW, organizador. A americanização (perversa) da seguridade social no Brasil: estratégias de bem-estar e políticas públicas. Rio de Janeiro: Editora Revan/Universidade Cândido Mendes/Instituto Universitário de Pesquisas do Rio de Janeiro; 1998. p. 130-66.

59. Reis JRF. Cultura de direitos e Estado: os caminhos (in)certos da cidadania no Brasil. In: Morosini MVGC, Reis JRF, organizadores. Sociedade, Estado e direito à saúde. Rio de Janeiro: Escola Politécnica de Saúde Joaquim Venâncio, Fundação Oswaldo Cruz; 2007. p. 15-61.

60. Santos WG. Cidadania e justiça. Rio de Janeiro: Campus; 1979.

61. Draibe SM. O Welfare State no Brasil: características e perspectivas. Campinas: Núcleo de Estudos de Políticas Públicas, Universidade Estadual de Campinas; 1993. (Caderno de Pesquisa, 8).

62. Gadelha CAG. Desenvolvimento, complexo industrial da saúde e política industrial. Rev Saúde Pública 2006; 40(N Esp):11-23.

63. Campos MS. O casamento da política social com a família: feliz ou infeliz? In: Mioto RCT, Campos MS, Carloto CM, organizadoras. Familismo, direito e cidadania: contradições da política social. São Paulo: Cortez Editora; 2015. p. 21-44.

64. Zola MB. Práticas sociais, família e proteção social: um estudo acerca das políticas familiares em diferentes cidades/países. In: Mioto RCT, Campos MS, Carloto CM, organizadoras. Familismo, direitos e cidadania: contradições da política social. São Paulo: Cortez Editora; 2015. p. 45-93.

65. Mioto RCT, Dal Prá KR. Serviços sociais e responsabilização da família: contradições da política social brasileira. In: Mioto RCT, Campos MS, Carloto CM, organizadoras. Familismo, direitos e cidadania: contradições da política social. São Paulo: Cortez Editora; 2015. p. 147-78.

66. Nogueira RP. Capacidades humanas, desenvolvimento e políticas públicas. In: Rodrigues VA, organizador. Estudos e análises, 1. Brasília: Núcleo de Estidos em Saúde Pública, Universidade de Brasília/Observatório de Recursos Humanos em Saúde do Brasil/Núcleo de Estudos sobre Bioética e Diplomacia em Saúde, Fundação Oswaldo Cruz; 2013. p. 15-20.

67. Secretaria de Políticas Públicas de Emprego, Ministério do Trabalho e Emprego. Aspectos conceituais da vulnerabilidade social. Brasília: Ministério do Trabalho e Emprego; 2007. 


\section{Abstract}

Are concepts of vulnerability capable of influencing social practices and citizenship in the fields of health and social welfare? The article critically assesses this question through a comprehensiveinterpretative approach to hermeneutics-dialectics and a review of the literature produced on the theme in the last two decades. There is no vast theoretical output on the theme. However, although conceptually imprecise, the term "vulnerability" expands the understanding of the multiple factors that weaken subjects in the exercise of their citizenship. Professional action in the sphere of health and social welfare policies and the social imaginary are forged by the incorporation of concepts that can either reduce or reinforce vulnerabilities.

Social Assistance; Social Welfare; Health Policy

\section{Resumen}

¿Los conceptos de vulnerabilidad son capaces de influenciar prácticas sociales y producción de ciudadanía en los campos de la salud y asistencia social? Este artículo de reflexión crítica discute esta cuestión, mediante el enfoque comprensivo-interpretativo de la hermenéutica-dialéctica y el método de revisión de la literatura producida en las dos últimas décadas sobre el tema. No existe una vasta producción teórica que contemple la temática. No obstante, aunque sea conceptualmente impreciso, el término vulnerabilidad amplía la comprensión de los múltiples factores que debilitan a las personas en el ejercicio de su ciudadanía. Las acciones profesionales en el ámbito de las políticas de salud $y$ asistencia social y el imaginario social se forjan por la incorporación de conceptos que pueden tanto reducir como reforzar vulnerabilidades.

Asistencia Social; Bienestar Social;

Politica de Salud

Recebido em 21/Jun/2017

Versão final reapreasentada em 31/Out/2017

Aprovado em 07/Dez/2017 